\title{
Fetal Homeostasis in Maternal Malnutrition. II. Magnesium Deprivation
}

\author{
Joseph Dancis ${ }^{[22]}$, Dawn Springer, and Sidney Q. Cohlan \\ Department of Pediatrics, New York University School of Medicine, New York, New York, USA
}

\begin{abstract}
Extract
In rats, supplied with an adequate dietary intake of magnesium, the mean fetal magnesium concentration in plasma was $2.4 \mathrm{mEq} /$ liter compared with a maternal concentration of $1.6 \mathrm{mEq} / \mathrm{liter}$. Equilibrium dialysis experiments resulted in a disappearance of the fetal to maternal gradient, with maternal levels becoming slightly higher than fetal levels. Determination of ultrafiltrable magnesium concentrations also demonstrated a slightly lower binding capacity for magnesium in fetal plasma so that the fetal to maternal gradient reflected the unbound magnesium.

When a diet containing magnesium in a concentration of $0.88 \mathrm{mEq} / \mathrm{kg}$ (compared with a control diet containing $120 \mathrm{mEq} / \mathrm{kg}$ ) was introduced on day 2 of gestation, only one of eight pregnant rats bore a litter to term. If the diet was introduced on day 10 of gestation, pregnancy continued until term but there was an increased resorption rate and the surviving fetuses were small, weak, and anemic. Analyses of maternal muscle for magnesium, calcium, sodium, and potassium revealed normal concentrations, even though magnesium concentrations in plasma rapidly fell to $20 \%$ of the normal level. There appeared to be a reduction in bone magnesium. The significant changes in the fetus were a reduction in magnesium levels in plasma with a disappearance of the fetal to maternal gradient and an elevation in sodium levels. Analysis of the total fetus demonstrated a reduction in magnesium and potassium and an increase in calcium concentrations. The last was also evident in the placenta.

\section{Speculation}

"Fetal parasitism" as a general concept appears to be an over-simplification which can be defined with accuracy only by the study of deprivations of specific nutrients, and eventually by the interaction of such nutrients.
\end{abstract}

\section{Introduction}

A major advantage of mammalian reproduction is the protection that it affords the fetus against a potentially hostile environment. In the case of nutritional deprivation, maternal homeostatic mechanisms react in an attempt to maintain normal levels of organic and inorganic constituents in maternal blood, coincidentally protecting the fetus. When maternal homeostasis is breached, the placenta through its complex transport mechanisms may act as a second line of defense. Only if both fail is the fetus exposed to the risks of malnutrition.

Previous studies in this laboratory have explored the effectiveness of these defensive mechanisms on fetal homeostasis when the pregnant rat was subjected to nutritional deprivation of potassium or sodium [2]. 
We have now explored, in similar manner, the effects of deprivation of an essential divalent ion, magnesium.

\section{Materials}

The sodium-deficient test diet for rats (Hartroft formula) [3], omitting the salt mixture, was purchased [14]. The salts were mixed in our laboratory. To $950 \mathrm{~g}$ basic diet was added $33 \mathrm{~g}$ salt mix, $5 \mathrm{~g} \mathrm{NaCl}, 12 \mathrm{~g} \mathrm{KCl}$, and $8 \mathrm{~g} \mathrm{MgSO}_{4}$ (Table I). This constituted the control diet. The magnesium-deficient diet was the same with the omission of $\mathrm{MgSO}_{4}$ from the salt mix. The magnesium content, by analysis, was $120 \mathrm{mEq} / \mathrm{kg}$ for the control diet, and $0.88 \mathrm{mEq} / \mathrm{kg}$ for the deficient diet.

\section{Methods}

Pregnant rats were obtained commercially [15]. The diets were offered ad libitum beginning usually on days 9-10 of pregnancy, and for several experiments on day 2 of gestation. Maternal blood samples were obtained by incising the tail vein. The ammonium salt of heparin was used as anticoagulant. On day 21 of gestation the animals were anesthetized with $0.15 \mathrm{ml}(60 \mathrm{mg} / \mathrm{ml})$ sodium pentobarbital intraperitoneally, and a hysterotomy was performed delivering the fetuses into an isotonic saline bath kept at $37^{\circ}$. Fetuses were removed and dried and blood samples from severed axillary vessels collected into heparinized (ammonium salt) microcollecting tubes. The blood from two normal fetuses was pooled to provide a sufficient sample for analysis. The fetuses from the diet-deficient mothers were smaller so that the blood from three or four fetuses was pooled. In several experiments, two pooled samples were collected from one litter. The results were essentially the same, though in some instances the potassium level in plasma was appreciably higher in the second pool, probably as a result of fetal hy-

Table I. Diet ${ }^{1}$

\begin{tabular}{lrlr}
\hline \multicolumn{1}{c}{ Diet, g/kg } & \multicolumn{2}{c}{ Basic salt mixture, g } \\
\hline Cascin & 200.00 & $\mathrm{Ca} \mathrm{CO}_{3}$ & 20.94 \\
Sucrose & 655.92 & $\mathrm{Ca}_{10}\left(\mathrm{OH}_{2}\left(\mathrm{PO}_{4}\right)_{6}\right.$ & 41.00 \\
Fiber, non-nu- & 20.00 & $\mathrm{Co} \mathrm{Cl}_{2}$ & 0.02 \\
$\quad$ & & \\
tritive & & $\mathrm{CuSO}_{4} \cdot 5 \mathrm{H}_{2} \mathrm{O}$ & 0.15 \\
Oil, corn & 70.00 & $\mathrm{FeCl}_{3} \cdot 6 \mathrm{H}_{2} \mathrm{O}$ & 4.65 \\
Vitamin supple- & 9.08 & $\mathrm{MnSO}_{1} \cdot \mathrm{H}_{2} \mathrm{O}$ & 0.40 \\
ments & & $\mathrm{NaI}$ & 0.014 \\
& & $\mathrm{Na}_{2} \mathrm{HPO}_{4}$ & 14.8 \\
& & $\mathrm{ZnSO}_{4} \cdot 7 \mathrm{H}_{2} \mathrm{O}$ & 0.116 \\
\hline
\end{tabular}

See text for salt content. poxia. Maternal muscle samples were obtained from the quadriceps, and bone samples from the femur.

\section{Preparation of Tissues}

All samples were prepared and analyzed in duplicate. Approximately $1 \mathrm{~g}$ of maternal muscle and placenta was weighed, transferred to porcelain crucibles, and dried in an oven at $100^{\circ}$ overnight. Femurs of the mother were freed of adhering tissue by immersing in boiling, distilled water for $1 \mathrm{~min}$ before ashing. Three or four fetuses were pooled and homogenized, and an aliquot of approximately $\mathrm{l} \mathrm{g}$ was transferred to crucibles. The samples were reweighed following drying and transferred to a muffle furnace for $16 \mathrm{hr}$ at $450^{\circ}$. One milliliter hot $0.5 \mathrm{~N}$ nitric acid was added to dissolve the residue. The solutions were transferred to test tubes and placed in a boiling water bath for 10-30 min to digest any residual particles.

\section{Analyses}

Sodium and potassium were determined in a flame photometer. Analyses for calcium and magnesium were done on an atomic absorption spectrophotometer [16]. The $t$ test and standard errors of the mean were determined on a computer [17] with standard programs.

\section{Equilibrium Dialysis}

Maternal plasma and pooled fetal plasma were diluted with equal parts of Tris buffer, $0.15 \mathrm{M}$, adjusted to $\mathrm{pH} 7.4$ at $37^{\circ}$. Five milliliters diluted maternal plasma were placed in a test tube and equilibrated against $5 \% \mathrm{CO}_{2}-95 \% \mathrm{O}_{2}$. Into this was placed a dialysis bag containing $1 \mathrm{ml}$ of similarly diluted fetal plasma and a glass bead. The tube was stoppered and placed on an angle in a metabolic shaker [18] and agitated for $4 \mathrm{hr}$ at $37^{\circ}$. The concentration of magnesium in the maternal and fetal plasma was determined before and after dialysis. The casing [19] was washed for $4 \mathrm{hr}$ in distilled water, before use, to remove any contaminating magnesium. Free magnesium was also determined after ultrafiltration through a dialysis bag by the method of Toribara et al. [7].

\section{Results}

\section{Fetal Survival}

Eight rats were fed the magnesium-deficient diet on day 2 of gestation. Only one animal retained a litter of living fetuses on day 21. Examination of the remaining animals revealed evidence of recent pregnancy but no 
surviving fetuses. Three pregnant animals fed the control diets had healthy live litters on day 21 of gestation. This conforms with our previous experience with the control diet [1].

Seventeen rats were fed the magnesium-deficient diet on days 9 or 10 of gestation. All produced live litters on day 21 with an average number of 8.1 fetuses. Examination of the uteri, however, revealed evidence of 36 resorptions. Of 12 animals fed the control diet, the litter number averaged 8.5 and there were no resorptions. The adverse effect of magnesium deprivation on reproductive performance has been previously noted [9].

Table II. Magnesium levels in blood in pregnant rats

\begin{tabular}{lccc}
\multirow{2}{*}{ Diet } & \multicolumn{3}{c}{ Magnesium, mEq/liter } \\
\cline { 2 - 4 } & 10 days $^{1}$ & 17 days & 21 days \\
\hline \multirow{2}{*}{ Control } & 1.39 & 1.29 & 1.55 \\
& 1.39 & 1.43 & 1.49 \\
& 0.87 & 1.41 & 1.79 \\
& 2.14 & 1.95 & 1.88 \\
& 1.60 & 1.84 & 1.80 \\
\multirow{3}{*}{ Mean } & 1.48 & 1.58 & 1.70 \\
& & & \\
& 1.43 & 0.27 & 0.27 \\
& 1.37 & 0.31 & 0.23 \\
& 1.27 & 0.31 & 0.21 \\
& 1.50 & 0.13 & 0.10 \\
& 1.37 & 0.20 & 0.13 \\
& 1.37 & 0.25 & 0.20 \\
& 1.39 & 0.25 & 0.19 \\
\hline
\end{tabular}

Days gestation.

\section{Effect on the Mother}

Rats fed the magnesium-deficient diets were generally distinguishable from the control animals only by the hyperemic ears characteristic of magnesium deficiency [4]. On occasion, the fur became slightly matted; however, they remained vigorous and ate well.

The blood magnesium level was monitored during pregnancy in several of the animals (Table II). The blood levels in the control animals rose slightly during pregnancy from a mean of 1.48 to $1.70 \mathrm{mEq} /$ liter. In contrast to this slight change, magnesium levels in the plasma of experimental animals after 11 days on the deficient diet were reduced to a mean of $14 \%$ of the initial levels. In four animals tested 4 days after introducing the deficient diet the magnesium levels in plasma had already fallen to a mean of $0.47 \mathrm{mEq} /$ liter.

In contrast to the rapid and extreme effect on circulating magnesium levels, the remaining chemical determinations remained remarkably stable (Table III). The mean bone magnesium concentration dropped appreciably (from 213 to $176 \mathrm{mEq} / \mathrm{kg}$ ), but this was not statistically significant, possibly because of the wide variation of values in both the control and experimental groups. Muscle composition remained unaltered.

\section{Effect on the Fetus}

Surviving fetuses were obviously damaged by the magnesium deprivation. They were small with a mean weight of $2.6 \pm 0.1 \mathrm{~g}$ in comparison with the control

Table III. Electrolyte concentrations in maternal and fetal tissues ${ }^{1}$

\begin{tabular}{|c|c|c|c|c|c|c|c|c|c|}
\hline & \multicolumn{4}{|c|}{ Maternal tissues } & & \multicolumn{4}{|c|}{ Fetal tissues } \\
\hline & $\mathrm{Mg}$ & $\mathrm{Ca}$ & $\mathrm{Na}$ & $\mathrm{K}$ & & $\mathbf{M g}$ & $\mathrm{Ca}$ & $\mathrm{Na}$ & $\mathrm{K}$ \\
\hline $\begin{array}{l}\text { Plasma } \\
\text { Control }\end{array}$ & $\begin{array}{c}1.6 \pm 0.04 \\
(15)\end{array}$ & $\begin{array}{c}5.0 \pm 0.68 \\
(13)\end{array}$ & $\mid \begin{array}{c}136 \underset{(11)}{ \pm} 1.4 \\
\mid\end{array}$ & $5.6 \underset{\text { (11) }}{ \pm} 0.41$ & $\begin{array}{l}\text { Plasma } \\
\text { Control }\end{array}$ & $2.4 \pm 0.07$ & $\begin{array}{c}4.9 \pm 0.10 \\
(19)\end{array}$ & $131 \underset{(13)}{ \pm} 1.5$ & $6.7 \pm 0.54$ \\
\hline Deficient & $0.33 \underset{(18)}{ \pm} 0.032$ & $\begin{array}{c}5.3 \pm 0.16 \\
(13)\end{array}$ & $\mid \begin{array}{c}140 \pm 2.0 \\
(13)\end{array}$ & $\begin{array}{c}5.3 \pm 0.24 \\
(13)\end{array}$ & Deficient & $\begin{array}{c}0.31 \pm 0.022 \\
(29)\end{array}$ & $\begin{array}{c}4.9 \pm 0.14 \\
(20)\end{array}$ & $\begin{array}{c}137 \pm 1.78 \\
(14)\end{array}$ & $\begin{array}{c}6.1 \pm 0.13 \\
\text { (11) }\end{array}$ \\
\hline $\begin{array}{l}\text { Bone } \\
\text { Control (8) }\end{array}$ & $213 \pm 13.7$ & $6.39 \pm 0.404$ & - & $47 \pm 1.2$ & $\begin{array}{l}\text { Placenta } \\
\text { Control }\end{array}$ & $8.8 \underset{(10)}{0.15}$ & $10.6 \pm 2.2$ & - & $\begin{array}{l}57 \pm 3.7 \\
\text { (11) }\end{array}$ \\
\hline Deficient (10) & $176 \pm 12.1$ & $6.70 \pm 0.474$ & - & $46 \pm 2.9$ & Deficient & $\begin{array}{c}7.8 \underset{(15)}{ \pm} 0.50 \\
\text { (1) }\end{array}$ & ${ }_{(12)}^{27.0}{ }_{\left(1.8^{2}\right.}^{ \pm}$ & - & $\begin{array}{l}51 \pm 2.8 \\
\quad(13)\end{array}$ \\
\hline $\begin{array}{l}\text { Muscle } \\
\text { Control }\end{array}$ & $\begin{array}{l}23 \pm 0.8 \\
(10)\end{array}$ & $\begin{array}{l}3.5 \underset{(8)}{ \pm} 0.62 \\
(8)\end{array}$ & - & 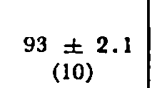 & $\begin{array}{l}\text { Fetus } \\
\text { Control }\end{array}$ & $14.2 \underset{\text { (14) }}{ \pm} 0.39$ & $80.1 \pm 3.7$ & - & $57.0 \underset{(14)}{ \pm} 1.5$ \\
\hline Deficient & $\begin{array}{l}24 \pm 0.5 \\
\text { (15) }\end{array}$ & $\begin{array}{c}4.2 \pm 0.53 \\
\text { (13) }\end{array}$ & - & $90 \underset{(15)}{ \pm}$ & Deficient & $\underset{(18)}{8.9} \underset{0.222}{ \pm}$ & $\underset{(15)}{105.0 \pm 5.0^{2}}$ & & $\int_{(18)}^{51.7} \pm 1.58$ \\
\hline
\end{tabular}

1 Values in $\mathrm{mEq} / \mathrm{liter}$ or per $\mathrm{kg} \pm \mathrm{sEM}$. Number of observations in parentheses.

IP $<0.01$.

$3 P<0.02$.

- Equivalents $/ \mathrm{kg}$.

I $P<0.05$. 
mean weight of $3.8 \pm 0.3 \mathrm{~g}$. They were pale, weak, and at times edematous.

Hematological studies revealed a consistent microcytic anemia, at times very severe. Edema was prominent in the severely anemic fetuses. These observations will be presented in greater detail [1].

The magnesium concentration in the plasma of experimental animals was drastically reduced, reaching a mean of $0.31 \mathrm{mEq} /$ liter, compared with concentrations of $2.4 \mathrm{mEq} /$ liter in the control fetuses. Sodium levels in the experimental animals were slightly increased, possibly as a result of similar increases in the mothers. Potassium and calcium concentrations were unaltered.

The magnesium concentration in the placenta of the experimental animals was only slightly lower than that found in the controls, the difference not being statistically significant. The mean calcium concentration, however $(27 \mathrm{mEq} / \mathrm{kg})$, was over twice the control value $(10.6 \mathrm{mEq} / \mathrm{kg})$.

Chemical analysis of the total fetus revealed statistically significant reductions in the concentrations of magnesium and potassium and an increase in calcium levels in the experimental animals (Table III).

\section{Fetal to Maternal Gradient of Magnesium in Plasma}

The level of magnesium in plasma of the fetus under control conditions is consistently higher than it is in the mother (mean of $2.4 \mathrm{mEq} /$ liter compared with 1.6 $\mathrm{mEq} /$ liter). This was not true of calcium (Table III). The mean fetal to maternal gradient of magnesium in the animals on the control diet was $1.54 \pm 0.04$ (SEM in 24 observations). In experimental animals, the relation of fetal and maternal plasma magnesiums was variable. On the average the gradient disappeared, the mean level in the fetus being $0.31 \mathrm{mEq} /$ liter compared with $0.33 \mathrm{mEq} / \mathrm{liter}$ in the mother. In three pregnant rats a less severe hypomagnesemia was induced in the

Table IV. Equilibrium dialysis of maternal and fetal plasma ${ }^{1}$

\begin{tabular}{ccccccccc}
\hline & \multicolumn{3}{c}{ Before dialysis } & & \multicolumn{3}{c}{ After dialysis } \\
\cline { 2 - 4 } \cline { 7 - 8 } \cline { 6 - 8 } & Maternal & Fetal & $\begin{array}{c}\text { Fetal: } \\
\text { maternal }\end{array}$ & & Naternal & Fetal & $\begin{array}{c}\text { Fetal: } \\
\text { maternal }\end{array}$ \\
\hline \multirow{2}{*}{1} & 1.78 & 3.24 & 1.82 & & 1.94 & 1.58 & 0.81 \\
& 1.78 & 3.02 & 1.70 & & 1.94 & 1.74 & 0.90 \\
2 & 2.06 & 2.80 & 1.36 & & 2.14 & 2.10 & 0.98 \\
& 1.94 & 2.90 & 1.49 & & 2.10 & 2.05 & 0.98 \\
\hline
\end{tabular}

1 Plasma was collected at 21 days gestation from fetuses and mothers fed control diets, the former being collected in two separate pools. Equilibrium dialysis was performed as described in the text. Concentrations are reported in milliequivalents per liter, corrected for dilution by Tris buffer. mother with a diet containing $3.4 \mathrm{mEq} / \mathrm{kg}$ magnesium. Although a fetal to maternal gradient was maintained, the fetal levels were also decreased.

Equilibrium dialysis of maternal versus fetal plasma was undertaken in control animals to exclude protein binding of magnesium as the cause of the gradient [8]. Under the conditions of the dialysis, there was actually a reversal of the gradient (Table IV), the maternal level becoming slightly higher than the fetal.

As a second approach to the same problem, the ultrafiltrable magnesium concentration [7] was determined in three pregnant rats fed control diets. In the mothers, the ultrafiltrable magnesium represented $0.60,0.57$, and 0.59 of the total, and the comparable figures in the fetuses were $0.69,0.63$, and 0.76 . The fetal to maternal gradients for total magnesiums in these three animals were 2.0,2.2, and 1.7; and the comparable figures for unbound magnesium were 2.3, 2.4, and 2.1. These results confirm the conclusions suggested by the equilibrium dialysis experiments: the fetal to maternal gradient is maintained despite a reduced protein binding of magnesium in the fetal plasma.

\section{Discussion}

The pivotal role that magnesium plays in many essential metabolic processes has attracted considerable investigative effort and has been the subject of recent extensive reviews $[10,12]$. However, comparatively little attention has been paid to magnesium metabolism during pregnancy. Tufts and Greenberg [9] have reported that diets containing $5 \mathrm{mg}$ magnesium/100 g diet are about the minimum that will support breeding in rats. There is no information in the literature on the effect of magnesium deprivation on fetal blood levels or tissue composition.

Under control conditions, the plasma magnesium level in the fetus is higher than in the mother (Table III). The existence of such a gradient suggests an active transport role for the placenta. The magnesium in plasma exists not only as the free ion, however, but bound to plasma proteins and complexed to organic radicals [11]. In an attempt to evaluate the effect of protein binding, equilibrium dialysis was undertaken between maternal and fetal plasma. Under these conditions, the fetal-maternal gradient was actually slightly reversed (Table IV), suggesting a more avid binding by maternal proteins. This could reflect simply differences in protein concentration rather than a fundamental difference in the type of protein binding. Ultrafiltration studies confirmed the fact that the fetal to maternal gradient represented differences in concentrations of the unbound magnesium. 
These observations strongly suggest but do not prove that the fetal to maternal gradient is maintained by active transport in the placenta. However, conditions in vivo that may differentially affect protein binding in mother and fetus were not strictly reproduced in the experiments in vitro, nor were the levels of complexed ion and their rates of transfer across the placenta investigated.

The value to the fetus of the relatively elevated plasma levels is unknown. Possibly, the supply of this essential ion to rapidly growing fetal tissue is facilitated. The fetal to maternal gradient, however, clearly does not serve to protect the fetus against maternal hypomagnesemia. Under the severe conditions of these experiments, the gradient actually disappeared. With less severe levels of hypomagnesemia in the mother, in a limited number of experiments, the gradient was maintained but the magnesium concentration in the fetus was also reduced.

There appears to be relatively little protection of the fetus against magnesium deprivation of the mother. The amount of mobilizable magnesium in the adult rat is relatively limited, magnesium balance being dependent on the maintenance of a regular exogenous supply [8]. This was evident in the present studies, a significant fall in maternal magnesium levels in plasma occurring within a few days after the introduction of the deficient diet. After 10 days of diet, however, when plasma levels were drastically reduced, the concentration of magnesium in maternal muscle was unchanged. The concentration in maternal bone did fall, possibly offering a source of magnesium for the growing fetus. The difference in mean bone concentrations between control and deficient animals did not quite achieve statistical significance $(P>0.05)$, probably because of the relatively large variation within both groups.

With little maternal magnesium available, and with the placenta unable to prevent magnesium concentrations in plasma of the fetus from falling to extremely low levels, magnesium deprivation clearly affected fetal welfare. When the magnesium-deficient diet was instituted early in pregnancy, few fetuses survived until term. When the diet was introduced after 9 or 10 days of gestation, most fetuses survived though there was still an increased number of resorptions.

The fetuses that survived were severely affected by the nutritional deprivation (Fig. 1). They were small, pale, feeble, and edematous at times, and they frequently displayed subcutaneous hemorrhages. Hematological studies revealed a consistent microcytic anemia associated with erythroblastosis [1]. This effect of magnesium deprivation may be peculiar to the fetus, not having been reported in previous studies with older rats $[5,13]$.

There were also significant changes in the chemical composition of the fetus. Magnesium concentration in tissue was considerably reduced, again demonstrating a particular susceptibility of the fetus not as evident in the more mature animal. The increased calcium concentration may reflect the same mechanism that induces hypercalcemia in the magnesium-deprived rat. This has been attributed to modifications of parathyroid function [5]; however, the plasma levels of calcium in the present studies were unchanged. The alterations in tissue composition may reflect transport problems or other distortions of cellular metabolism.

It has often been stated that the fetus exists as a parasite within the maternal organism. By this it is implied that the fetus will derive essential nutrients from the mother despite maternal needs. There ap. pears to be significant differences among nutrients in the efficiency with which this is accomplished.

Previous studies in this laboratory explored the effects of deprivation of the two univalent ions, potassium and sodium, during pregnancy [2]. Maternal stores of both ions were considerably reduced to pro. vide the growing fetus with these materials. With potassium deprivation, although the mothers became sluggish, lost their appetites, and developed matted hair, the fetuses were alive and vigorous though a little small. The fetuses so effectively secured potassium from the mothers that the potassium levels in plasma were maintained at normal levels even though the

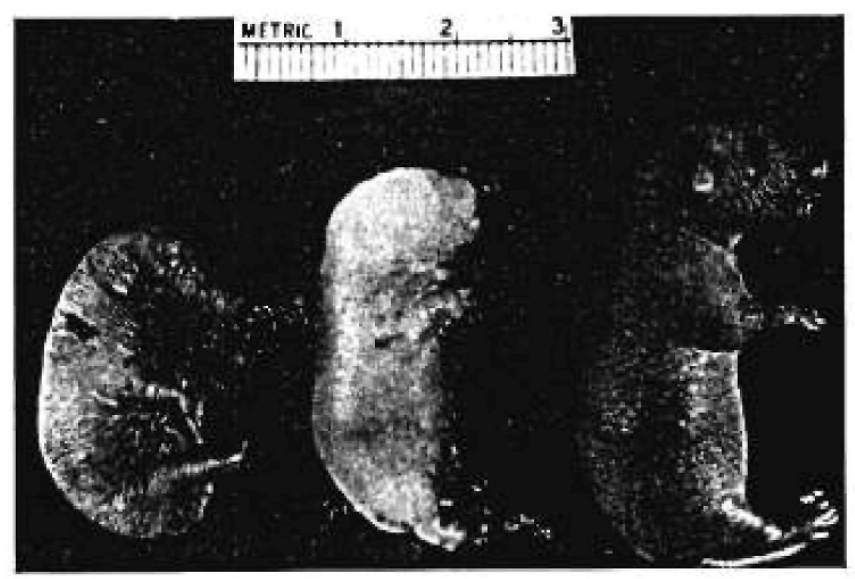

Fig. 1. Magnesium deficiency in fetal rats. Pregnant rats were fed a magnesium-deficient diet on day 10 of gestation, and fetuses were removed by hysterotomy on day 21. Control rat fetus on right; two runted magnesium-deprived rat fetuses on left. Occasional fetuses were severely anemic, hydropic with yellow-stained polyhydramnios (center). 
maternal levels were reduced by $50 \%[2,6]$. In the case of sodium deprivation, the placenta did not as effectively maintain a constant internal milieu for the fetus. As maternal compensatory mechanisms failed in their efforts to maintain normal sodium levels in plasma, fetal concentration also fell. The amount of reduction in the fetus was not quite so great as in the mother, suggesting limited protection.

Magnesium was next selected for study because it differs from sodium and potassium in several important characteristics. It is divalent and partially bound to proteins, and a gradient is maintained toward the fetus. The response of the pregnant rat to deprivation also differs significantly. Fetal parasitism did occur to a limited extent, in the sense that maternal magnesium was drained into the fetus. In the inevitable competition between mother and offspring, however, magnesium was retained by the mother at the expense of the fetus. The mothers looked healthy at term and, although hypomagnesemia occurred, tissue concentrations were only modestly reduced. In contrast, fetuses were severely damaged, and the tissues were starved of magnesium. This is contrary to the priorities for essential nutrients in pregnancy suggested by the term "fetal parasitism."

\section{Summary}

The concentration of magnesium in plasma in the fetal rat was consistently higher than that found in the mother if adequate amounts of magnesium were provided during pregnancy.

Equilibrium dialysis of maternal and fetal plasma and measurements of ultrafiltrable magnesium concentrations excluded protein binding as the mechanism for maintaining the fetal to maternal gradient. By inference, the gradient was probably maintained by the placenta.

On a sharply restricted magnesium intake, maternal magnesium concentration in plasma rapidly fell. Tissue concentration remained relatively inaffected and there were few systemic effects duning the brief period of study.

In contrast to the minor "effects on the mother, the fetus was dramatically affected. If the magnesium-deficient diet was introduçed on day 2 of gestation, the fetuses generally died and were resorbed. If the diet was introduced on day 10 of gestation, the fetuses survived until term but were small, weak, and anemic. Magnesium concentrations in plasma were reduced with the fetal to maternal gradient often obliterated.
Tissue concentrations of magnesium were also reduced, and there were secondary changes in tissue composition.

\section{References and Noles}

1. Collean, S. Q., Piomelli, S., Jansen, V., and Dancis, J.: Microcytic anemia with erythroblastosis in offspring of magnesium-deprived rats. Blood, 36: 500 (1971).

2. Dancis, J., And SPRinger, D.: Fetal homeostasis in maternal malnutrition: Potassium and sodium deficiency. Pediat. Res., 4: 345 (1970).

3. Hartroft, P. M., and Eisenstein, A. B.: Alterations in the adrenal cortex of the rat induced by sodium deficiency: Correlation of histologic changes with steroid hormone secretion. Endocrinology, 60: 641 (1957).

4. Kruse, H. D., Orent, E. R., and McCollum, E. V.: I. Symptomatology resulting from magnesium deprivation. J. Biol. Chem., 96: 519 (1932).

5. Macintyre, I., Boss, S., ANd Troughton, V. A.: Parathyroid hormone and magnesium homeostasis. Nature, 198: 1058 (1963).

6. Stewart, E. L., and Welt, L. G.: Protection of the fetus in experimental potassium depletion. Amer. J. Physiol., 200: 824 (1961).

7. Toribara, T. Y., Terepka, A. R., and Deiney, P. A.: The ultrafiltrable calcium of human serum. I. Ultrafiltration methods and normal values. J. Clin. Invest., 36: 738 (1957).

8. Tufts, E. V., And GreenderG, D. M.: The biochemistry of magnesium deficiency. I. Chemical changes resulting from magnesium deprivation. J. Biol. Chem., 122: 693 (1938).

9. Tufts, E. V., And Greenberc, D. M.: The biochemistry of magnesium deficiency. II. The minimum magnesium requirement for growth, gestation and lactation, and the effect of the dictary calcium level thercon. J. Biol. Chem., 122: 715 (1938).

10. Whacker, W. E. C., ANd Parisi, A. F.: Magnesium metabolism. New Engl. J. Med., 278: 658, 712, 772 (1968).

11. WALSER, M.: Ion association. VI. Interactions between calcium, magnesium, inorganic phosphate, citrate and protein in normal human plasma. J. Clin. Invest., 40: 723 (1961).

12. Walser, M.: Magnesium metabolism. Ergeb. Physiol. Biol. Chem. Exp. Pharmakol., 59: 185 (1967).

13. Whanc, R., AND IVELT, L. G.: Observations in experimental magnesium depletion. J. Clin. Invest., 42: 305 (1963).

14. No. 170950, General Biochemicals Co., Chagrin Falls, O.

15. Charles River Breeding Laboratories, Inc., Wilmington, Mass.

16. Perkin-Elmer Corporation, Norwalk, Conn.

17. Programma 101, Olivetti Underwood, New York, N.Y.

18. Dubnoff, Fisher Scientific Company, New York, N.Y.

19. Visking, Will Scientific, Inc., New York, N.Y.

20. J. Dancis is a Career Investigator, National Institute of Child Health and Human Development.

21. Aided by National Institute of Child Health and Human Development Grants nos. HD 00462 and HD 00187.

22. Requests for reprints should be addressed to: Joseph Dancis, M.D., Department of Pediatrics, New York University Medical Center, 550 First Avc., New York, N.Y. 10016 (USA).

23. Accepted for publication March 13, 1970. 